Fakultas Hukum, Universitas Lampung, Bandar Lampung, Lampung, Indonesia. http://jurnal.fh.unila.ac.id/index.php/corruptio

Volume 01 Issue 2, July-December 2020. PP: 129-142

P-ISSN: 2723-2573

E-ISSN: 2745-9276

\title{
Studi Komparatif Antara Justice Collaborator Dengan Whistleblower Dalam Tindak Pidana Korupsi
}

\section{Comparative Study Between Justice Collaborator And Whistleblower In Criminal Actions Of Corruption}

\author{
Laura Naomi Rotua Gultom
}

laura@gmail.com

Magister Hukum Universitas Lampung

Submitted: August 21, 2020; Reviewed: Sept 23, 2020; Accepted: Okt 12, 2020

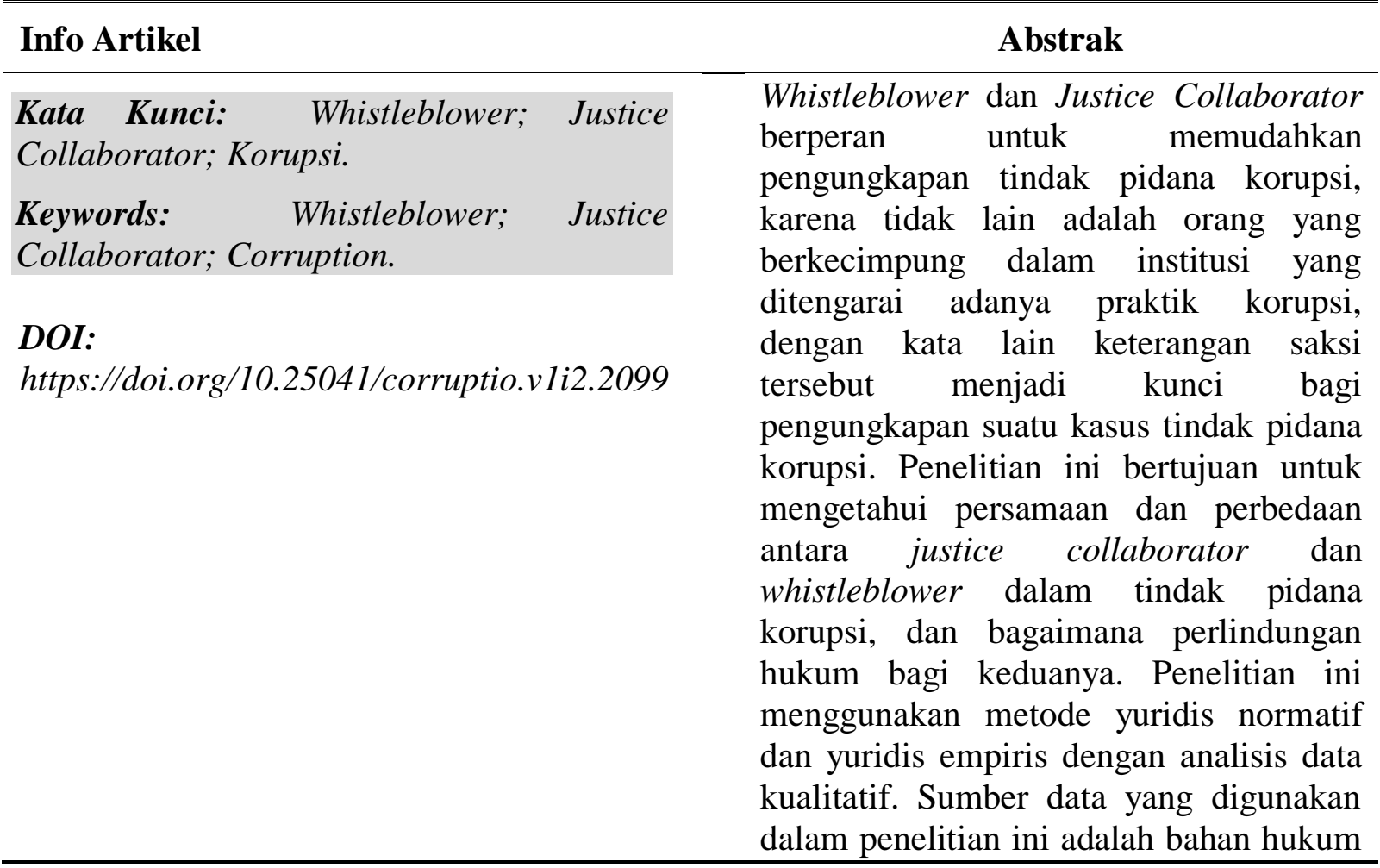


primer, sekunder, dan tersier. Hasil penelitian ini menunjukan bahwa persamaan whistleblower dan justice collaborator terdapat pada 3 (tiga) kategori yaitu visi dan misi dalam mengungkap tindak pidana korupsi, jaminan perlindungan baik berupa perlindungan fisik, psikis, dan hukum, dan penghargaan dimana whistleblower dan justice collaborator tidak dapat dituntut pidana dan perdata serta diberikan keringanan hukuman. Selain persamaan tersebut, terdapat juga perbedaan antara whistleblower dan justice collaborator terbagi dalam 4 (empat) kategori, yaitu subjek, motivasi, jaminan perlindungan, dan hukum acara. Adapun perlindungan antara justice collaborator dan whistleblower dalam tindak pidana korupsi yaitu perlindungan hukum berupa merahasiakan identitas saksi dan memberikan pengamanan terhadap saksi dalam proses persidangan baik perlindungan fisik, psikis, dan hukum.

Abstract
The Whistleblower and Justice
Collaborator play a role in facilitating the
disclosure of criminal acts of corruption,
because none other than people involved
in institutions suspected of corrupt
practices and in other words the witness's
information is key for disclosure of a
case of corruption. The problem in this
study is whether the similarities and
differences between justice collaborator
and whistleblowers in corruption, and
how is the legal protection between
justice collaborator and whistleblower in
criminal acts of corruption. This research
uses normative juridical and juridical
empirical research methods with
qualitative data analysis. The data
sources used in this study are primary,
secondary, and tertiary legal materials.
The results showed that whistleblower
equations and justice collaborator were in
3 (three) categories, namely vision and


mission in uncovering criminal acts of corruption, guarantee of protection in the form of physical, psychological and legal protection, and awards where whistleblowers and justice collaborators cannot be prosecuted criminal and civil and given sentence relief. In addition to these equations, there are also differences between whistleblowers and justice collaborator divided into 4 (four) categories, namely subject, motivation, guarantee of protection, and procedural law. The protection between justice collaborator and whistleblower in corruption namely legal protection in the form of keeping the identity of the witness confidential and then provides security for witnesses in the trial process by providing physical, psychological, and legal protection.

\section{A. Pendahuluan}

Negara demokrasi merupakan interpretasi dari kedaulatan rakyat, bahwa negara sebesarbesarnya adalah milik rakyat. Penguasa dan rakyat merupakan kesatuan yang tidak dapat dipisahkan, sebab syarat berdirnya suatu negara meliputi adanya rakyat, pemerintahan, wilayah kekuasaan, dan diakui serta menjalin hubungan dengan negara lain. ${ }^{1}$ Perkembangan peradaban dunia semakin hari berkembang menuju modernisasi. Perkembangan yang selalu membawa perubahan dalam setiap sendi kehidupan tampak lebih nyata. Seiring dengan itu pula bentukbentuk kejahatan juga senantiasa mengikuti perkembangan zaman dan bertransformasi dalam bentuk-bentuk yang semakin canggih dan beraneka ragam. Salah satu tindak1 pidana yang sekarang fenomenal dan sangat merugikan negara adalah masalah korupsi. ${ }^{2}$ Dengan maraknya tindak pidana korupsi yang terjadi di Indonesia dewasa ini, sudah tentu hukum harus kembali mengambil peranannya sebagai sarana atau alat untuk mengatur ketertiban umum dan memulihkan keseimbangan dalam kehidupan bermasyarakat, berbangsa dan bernegara. ${ }^{3}$

Semakin hari pembicaraan mengenai korupsi tidak pernah berhenti, angka pertumbuhan korupsi di Indonesia semakin meningkat menjadi 263 kasus dengan jumlah kerugian negara yang sudah mencapai Rp 6,5 triliun dan suap yang mencapai $\mathrm{Rp} 211$ miliar sampai pertengahan tahun 2018. ${ }^{1}$ Secara harfiah istilah korupsi adalah segala macam perbuatan yang tidak baik, seperti yang dikatakan Andi Hamzah sebagai kebusukan, keburukan, kebejatan, ketidak jujuran, dapat disuap, tidak bermoral, penyimpangan dari kesucian, kata-kata atau ucapan yang menghina atau memfitnah. ${ }^{4}$ Untuk itu perlu dilakukan penegakan hukum sebagai suapaya

\footnotetext{
${ }^{1}$ Shandi Patria Airlangga, "Hakikat Penguasa Dalam Negara Hukum Demokratis The Nature Of The Authorities In A Democratic Rule Of Law,” Cepalo, 2019, https://doi.org/10.25041/cepalo.v3no1.1783. hlm 2.

${ }^{2}$ Sukino, "PERTANGGUNGJAWABAN PENGGUNA ANGGARAN TERHADAP TINDAK PIDANA KORUPSI DANA BANTUAN SOSIAL (STUDI PUTUSAN MA.NO. 995 K/PID.SUS/2017),” Ensiklopedia of Journal 1, no. 4, July 8, 2019 : 91-96, http://jurnal.ensiklopediaku.org. hlm 92 .

3 Yopi Gunawan and Universitas Singaperbangsa Karawang, "PERAN DAN PERLINDUNGAN WHISTLEBLOWER (PARA PENGUNGKAP FAKTA) DALAM RANGKA MEMBERANTAS TINDAK PIDANA KORUPSI DI INDONESIA," Law Review, vol. XVIII, May 18, 2019, https://ojs.uph.edu/index.php/LR/article/view/1201. hlm 270.

${ }^{4}$ Andi Hamzah, Korupsi di Indonesia, (Jakarta: Sinar Grafika), hlm.7
} 
dalam penyelenggaraan kehidupan bangsa dan negara untuk menjamin kepentingan mayoritas masyarakat atau warga negara, dapat menjamin kepastian hukum, keadilan, dan kebenaran serta mengahargai hak asasi manusia, sehingga berbagai tindakan kriminal dan tindakan semenamena yang dilakukan anggota masyarakat atas anggota masyarakat lainnya akan dapat dihindarkan. ${ }^{5}$

Di Indonesia, pengaturan mengenai whistleblower dan jusce collaborator diatur dalam berbagai peraturan perundang-undangan baik undang-undang, peraturan pemerintah, surat edaran Mahkamah Agung, peraturan Kapolri, peraturan bersama, surat edaran Menteri, dan lain sebagainya. $^{6}$ Keberadaaan justice collaborator dalam suatu kepastian hukum untuk mendapatkan perlindungan yang jelas bagi pelaku yang dinyatakan sebagai justice collaborator. Seorang justice collaborator terbukti bersalah dalam kasusn yang sama maka ia tidak dapat dibebaskan dari pidana. ${ }^{7}$ Untuk itu pentingnya justice collaborator dalam kasus tindak pidana korupsi, sebab melihat betapa pentingnya peran justice collaborator dalam membongkar dan memberantas tindak pidana korupsi maka diperlukan payung hukum yang kuat dalam mengatur dan melindungi justice collaborator. ${ }^{8}$

Justice collaborator memilki pengertian dari konsep yang termuat dalam SEMA Nomor 4 Tahun 2011 tentang Pelakuan Bagi Pelapor Tindak Pidana (Whistleblower) dan Saksi Pelaku yang bekerjasama (justice collaborator) di dalam perkara tindak pidana tertentu, namun demikian dalam dalam pelaksanaannya beberapa system diats belum mampu terlaksana dengan maksimal dikarenakan tidak ada aturan yang secara rinci mengatur mekanisme pelaksanaan dari system tersebut terutama terkait perlindungan dan penghargaan yang dapat diberikan, ${ }^{9}$

Korupsi pada umumnya dilakukan oleh orang yang memiliki kekuasaan dalam suatu jabatan, sehingga karakteristik kejahatan korupsi selalu berkaitan dengan penyalahgunaan kekuasaan dalam perspektif kejahatan yang terorganisir. ${ }^{10}$ Tindak pidana korupsi yang meluas dan sistematis juga merupakan pelanggaran terhadap hak-hak sosial dan hak-hak ekonomi masyarakat, oleh karena itu semua tindak pidana korupsi tidak lagi dapat digolongkan sebagai kejahatan biasa, namun telah menjadi suatu kejahatan luar biasa (extra ordinary crime). Oleh karena itu diperlukan penegakan hukum yang komprehensif. ${ }^{11}$

Beberapa modus operandi korupsi yaitu sebagai berikut:

1. Penggelapan; tindak pidana korupsi penggelapan antara lain ditandai dengan adanya para pelaku, seperti menggelapkan aset-aset harta kekayaan negara atau keuangannegara untuk memperkaya dirinya sendiri atau orang lain.

2. Pemerasan; bentuk tindak pidana korupsi pemerasan antara lain dengan ditandainya adanya pelaku seperti memaksa seorang secara melawan hukum yang berlaku agar memberikan sesuatu barang atau uang kepada yang bersangkutan.

3. Penyuapan; bentuk tindak pidana korupsi penyuapan antara lain ditandai adanya para

\footnotetext{
5 Yayan Indriana, "Pengembalian Ganti Rugi Keuangan Negara Pada Perkara Tindak Pidana Korupsi," Cepalo 2, no. 2 (September 12, 2019), https://jurnal.fh.unila.ac.id/index.php/cepalo/article/view/1769. hlm 125.

${ }^{6}$ Lilik Mulyadi, "Perlindungan Hukum Whistle-Blower Dan Justice Collaborator Dalam Upaya Penanggulangan Organized Crime Di Indonesia Masa Mendatang,” PADJADJARAN Jurnal Ilmu Hukum (Journal of Law) 1, no. 3 (2014): 578-97, https://doi.org/10.22304/pjih.v1n3.a9.

7 Ni Luh Made Dwi Pusparini, et al. "Urgensi Saksi Pelaku Yang Bekerjasama (Justice Collaborator) Dalam Tindak Pidana Korupsi,"Jurnal Interpretasi Hukum, $\quad$ Vol. $\quad 1 ., \quad$ No. $\quad 1, \quad$ 2020: $179-185$. https://www.ejournal.warmadewa.ac.id/index.php/juinhum/article/view/2207/1606. hlm 181.

${ }^{8}$ Eko Soponyono, Pujiyono, "Kebijakan Formulasi Hukum Pidana Terhadap 'Justice Collaborator' Dalam Tindak Pidana Korupsi Di Indonesia." Diponegoro Law Journal, Vol. 1 No. 4, 2020: 1-11, https://ejournal3.undip.ac.id/index.php/dlr/article/view/288/291. hlm 4.

${ }^{9}$ Ruchoyah, "Urgensi Plea Bargaining System Dalam Pembaruan Sistem Peradilan Pidana Di Indonesia: Studi Perbandingan Plea Bargaining System," Jurnal Hukum IUS QUIA IUSTUM 27, no. 2020 (August 25, 2020): 388-409, https://doi.org/10.20885/iustum.vol27.iss2.art9. hlm 390.

${ }^{10}$ Deyv Ch. Rumambi, "KORUPSI DALAM PERSPEKTIF HUKUM ADMINISTRASI NEGARA," LEX ET SOCIETATIS, vol. 2, August 15, 2014, https://ejournal.unsrat.ac.id/index.php/lexetsocietatis/article/view/5396.

${ }^{11}$ Halim, Pemberantasan Korupsi, (Jakarta: Rajawali Press, 2004). hlm.47
} 
pelakunya, seperti memberikan suap kepada oknum-oknum pegawai negeri agar si penerima suap memberikan kemudahan dalam pemberian izin, kredit bank dll. yang bertentangan dengan peraturan perundang-undangan yang berlaku.

4. Manipulasi; bentuk tindak pidana korupsi manipulasi antara lain ditandai dengan adanya para pelakunya yang melakukan mark-up proyek pembangunan, SPJ, pembiayaan gedung/kantor, pengeluaran anggaran fiktif.

5. Pungutan Liar; bentuk tindak pidana korupsi pungutan liar, di mana para pelakunya yang malakukan pungutan liar di luar ketentuan peraturan. Umumnya pungutan liar ini dilakukan terhadap seseorang/ koorporasi apabila ada kepentingan atau berurusan dengan instansi pemerintah.

6. Kolusi dan Nepotisme; yaitu pengangkatan sanak saudara, teman-teman atau kelompok politiknya pada jabatan-jabatan dalam kedinasan aparat pemerintah tanpa memandang keahlian dan kemampuan.

Pemerintah dalam rangka mewujudkan supremasi hukum, telah meletakkan kebijakan yang kuat dalam memerangi tindak pidana korupsi. Berbagai kebijakan tersebut tertuang dalam berbagai peraturan perundang-undangan, antara lain Ketetapan Majelis Permusyawaratan Republik Indonesia Nomor XI/MPR/1998 tentang Penyelenggara Negara yang Bersih dan Bebas Korupsi, Kolusi dan Nepotisme. Undang-Undang Nomor 28 Tahun 1999 tentang Penyelenggara Penyelenggara Negara yang Bersih dan Bebas Korupsi, Kolusi dan Nepotisme serta Undang-Undang Nomor 31 Tahun 1999 sebagaimana diubah menjadi Undang-Undang Nomor 20 Tahun 2001 tentang Pemberantasan Tindak Pidana Korupsi. ${ }^{12}$

Proses penyelesaian perkara tindak pidana korupsi yang menjadi hal terpenting untuk mengungkap kasus korupsi adalah alat bukti yang secara sah diakui oleh Undang-Undang berdasarkan Pasal 184 Ayat 1 KUHAP adalah: ${ }^{13}$
a. Keterangan Saksi
b. Keterangan Ahli
c. Surat
d. Petunjuk
e. Keterangan Terdakwa

Dalam sistem pembuktian hukum acara pidana yang menganut stelsel negatief wettelijk, hanya alat-alat bukti yang sah menurut undang-undang yang dapat dipergunakan untuk pembuktian. ${ }^{14}$ Pembuktian di persidangan memerlukan alat bukti yang sah, salah satunya adalah keterangan saksi.

Keterangan saksi adalah salah satu bukti dalam perkara pidana yang merupakan keterangan dari saksi mengenai suatu peristiwa pidana yang ia dengar sendiri, ia lihat sendiri, dan ia alami sendiri dengan menyebut alasan dari pengetahuannya itu. ${ }^{15}$ Pada umumnya alat bukti yaitu keterangan saksi merupakan hal yang utama pada perkara pidana, atau dapat dikatakan suatu perkara pidana tidak terlepas dari alat bukti keterangan saksi yang menjadi

12 M Saoki Oktava, "EKSISTENSI KETETAPAN MPR/S DALAM HIERARKI PERATURAN PERUNDANGUNDANGAN DI INDONESIA THE EXISTENCE OF MPR/S PROVISION IN HIERARCHY OF LAWS AND REGULATIONS IN INDONESIA," Jurnal IUS Kajian Hukum Dan Keadilan, vol. 5, April 27, 2004: 120-142, http://jurnalius.ac.id/ojs/index.php/jurnalIUS/article/view/434. hlm 120.

${ }^{13}$ Moejijat, "Kesesuaian Upaya Pembuktian Jaksa Penuntut Umum Terhadap Tindak Pidana Pembunuhan Berdasarkan Alat Alat Buktiyang Sah Dengan Ketentuan Pasal 184 Kuhap (Studi Putusan Nomor: 171/PID.B/2012/PN.Mgt)." Verstek, accessed October 16, 2020, https://jurnal.uns.ac.id/verstek/article/view/39115/25801. hlm 20.

${ }^{14}$ Wirjono Prodjodikoro, Tindak-Tindak Pidana Tertentu di Indonesia, (Jakarta- Bandung: Eresco) hlm. 15.

15 Nur Fitriani, "TINJAUAN YURIDIS KEKUATAN PEMBUKTIAN KETERANGAN SAKSI ANAK DALAM PERSIDANGAN PERKARA PIDANA JURIDICAL REVIEW OF THE POWER OF EVIDANCE OF CHILDREN'S WITNESS EVENTS IN CRIMINAL TRIALS,” JURNAL LEGALITAS, vol. 12, January 3, 2019, http://ejurnal.ung.ac.id/index.php/JL/article/view/5416. hlm 15. 
dasar pertimbangan hakim dalam memutus sebuah perkara tindak pidana korupsi. ${ }^{16}$

Salah satu hal yang menarik perhatian adalah munculnya istilah whistleblower dan justice collaborator. ${ }^{17}$ Istilah ini meskipun telah dikenal lama dan digunakan di beberapa negara, namun Indonesia masih relatif baru dalam referensi hukum pidana. Istilah justice collaborator (selanjutnya disebut JC) sering disalahartikan dengan whistleblower (selanjutnya disebut WB). Antara JC dan WB memiliki status hukum yang berbeda. Karena keduanya hampir sangat mirip, maka sebagai pembeda antara whistleblower dan justice collaborator diciptakan sebuah peraturan yang disetujui oleh beberapa lembaga penegak hukum, yaitu Kemenkumham, Kejaksaan Agung, Kepolisian, KPK, LPSK. Peraturan yang dibuat ditujukan untuk mengatur terkait perlindungan saksi pelapor dan saksi pelaku yang mau bekerjasama dengan penegak hukum. ${ }^{18}$

Penggunaan saksi Justice Collaborator dalam peradilan pidana merupakan salah satu bentuk upaya luar biasa yang dapat digunakan untuk memberantas tindak pidana korupsi yang melibatkan pelaku tindak pidana itu sendiri, dimana pelaku tersebut bersedia bekerjasama dengan aparat penegak hukum dalam membongkar kejahatan korupsi. Selain itu, seorang justice collaborator juga diharapkan dapat terbantu dalam proses pemberian vonis pidana, meskipun tidak dapat dibebaskan dari tuntutan pidana apabila ternyata terbukti secara sah dan meyakinkan bersalah, tetapi kesaksiannya dapat dijadikan pertimbangan hakim dalam meringankan pidana yang dijatuhkan baginya. Dalam justice collaborator inisiatif untuk memberikan keterangan berasal dari diri pelaku yang dengan kesadarannya mengakui perbuatannya dan kemudian membantu penyidik untuk mengungkap keterlibatan pelaku lain dalam jaringan tindak pidana tersebut. Perbedaan lain "saksi mahkota" dilindungi dengan cara tidak diteruskan perkaranya, sedangkan justice collaborator dilindungi dan diberikan penghargaan berupa pnuntutan dan penghukuman yang lebih ringan. ${ }^{19}$

Sementara itu, whistleblower juga merupakan alat penting dalam melawan kejahatan terorganisir seperti dugaan tindak pidana korupsi. Sebagai orang dalam yang menjadi bagian dari lingkungan tempat informasi yang dia bocorkan, tentulah sangat paham mengenai apa dan bagaimana modus kejahatan yang selama ini terbungkus rapi dan bersifat rahasia bagi publik dan aparat hukum. Dalam peraturan perundang-undangan Indonesia whistleblower seringkali disamakan dengan pelapor. Dalam prakteknya dibedakan antara whistleblower dengan para pelapor dan informan. Perbedaan utamanya adalah para whistleblower tidak akan memberikan kesaksiannya ke muka persidangan (peradilan), jadi jika ia memberikan kesaksiannya ke muka persidangan maka statusnya menjadi saksi. ${ }^{20}$ Whistleblower memegang peran dalam membongkar bermacam pelanggaran hukum atau kejahatan, mal adminitrasi, kecurangan, mismanajemen, salah pengurusan, kelalaian yang memiliki dampak yang merugikan bagi publik.

Peran Whistleblower dan Justice Collaborator sangat penting dan diperlukan dalam proses pemberantasan tindak pidana korupsi. Keduanya berperan untuk memudahkan pengungkapan tindak pidana korupsi, dengan kata lain keterangan saksi tersebut menjadi kunci bagi pengungkapan suatu kasus tindak pidana korupsi. dimensi Whistleblower dan Justice Collaborator tidak hanya berorientasi sesuai konteks. Aspek ini lebih luas dapat dikatakan Whistleblower maupun Justice Collaborator dari perspektif formulasi serta

\footnotetext{
${ }^{16}$ Rusli Muhammad, "Pengaturan Dan Urgensi Whistle Blower Dan Justice Collaborator Dalam Sistem Peradilan Pidana," Jurnal Hukum IUS QUIA IUSTUM, vol. 22, 2015, https://journal.uii.ac.id/IUSTUM/article/view/5117.

${ }^{17}$ Firman Wijaya, Whistle Blower dan Justice Colaborator dalam Perspektif Hukum, (Jakarta: Penaku, 2012), hlm. 23.

18 Esti Kanti Pertiwi and Noor Rahmad, "TINJAUAN NORMA HUKUM JUSTICE COLLABORATOR DAN WHISTLEBLOWER PADA TINDAK PIDANA KORUPSI," Perspektif, vol. 25, May 29, 2020, https://www. hlm 93.

19 Ahmad Yunus, "Penetapan Pelaku Tindak Pidana Korupsi Sebagai Justice Collaborator." Simbur Cahaya," accessed October 16, 2020, http://journal.fh.unsri.ac.id/index.php/simburcahaya/article/view/54/54. hlm 4762.

${ }^{20} \mathrm{http}$ ://repository.widyatama.ac.id/bitstream/handle/10364/1024/bab1-2.pdf?sequence=3, diunduh pada hari Selasa, 16 Oktober 2018 Pukul 14.00 WIB
} 
praktiknya menimbulkan dilemaya itu dalam posisi bagaimana seseorang ditempatkan sebagai Whistleblower dan Justice Collaborator, ${ }^{21}$ Oleh karena itu, penelitian ini bertujuan untuk mengkaji dan meneliti bagaimana persamaan dan perbedaan dari Whistleblower dan Justice Collaborator dan bagaimana perlindungan hukum bagi keduanya dalam tindak pidana korupsi.

Pendekatan yang dilakukan dalam penelitian ini adalah pendekatan yuridis normatif dan yuridis empiris. Yakni dengan cara menelaah kaidah-kaidah, norma-norma, aturan-aturan yang berhubungan dengan masalah yang akan diteliti serta mengumpulkan data primer yang diperoleh secara langsung melalui observasi terhadap objek penelitian. Sumber data yang digunakan dalam penelitian ini adalah bahan hukum primer, sekunder, dan tersier.

\section{B. Pembahasan}

\section{Persamaan dan Perbedaan Justice Collaborator dan Whistleblower}

Seorang whistleblower dan Justice collaborator merupakan pelapor ada dugaan tindak pidana, atau pelaku dari tindak pidana yang dilaporkannya. Konsekuensi logis aspek tersebut, maka syarat untuk dapat dilindunginya seorang whistleblower dan Justice collaborator mengakui keterlibatannya dalam perkara yang bersifat organized crime, mau melakukan kerjasama yang integral, kooperatif dan partisipatif dengan aparat penegak hukum dalam mengungkapkan kasus tersebut, serta mau melakukan pengembalian terhadap kerugian yang ditimbulkan akibat tindak pidana bersifat organized crime.

Persamaan justice collaborator dan whistleblower antara lain:

a) Visi dan misi

Persamaan whistleblower dan justice collaborator adalah mengungkap tindak pidana korupsi.

b) Jaminan perlindungan

Whistleblower dan justice collaborator diberikan perlindungan fisik, psikis dan hukum.

c) Penghargaan

Whistleblower dan justice collaborator tidak dapat dituntut pidana maupun perdata, perlindungan dari pencemaran nama baik, perlindungan dari pembalasan dan perlindungan kondisional apabila namanya dipublikasikan ke media.

Perbedaan whistleblower dan justice collaborator antara lain:

a. Subjek

Whistleblower adalah masyarakat sedangkan justice collaborator adalah salah satu pelaku tindak pidana (bukan pelaku utama).

b. Motivasi

Whistleblower melaporkan atas kesadaran sendiri, sedangkan justice collaborator atas dasar tindakan kooperatif dengan aparat penegak hukum.

c. Hukum acara

Whistleblower memberikan keterangan diluar persidangan sedangkan justice collaborator memberikan keterangan didalam persidangan.

d. Jaminan perlindungan

Whistleblower dalam hal memberikan keterangan tertutup oleh media sedangkan justice collaborator dalam memberikan keterangan diketahui media dan di lindungi undangundang.

\footnotetext{
21 Suratno, "PERLINDUNGAN HUKUM SAKSI DAN KORBAN SEBAGAI WHISTLEBLOWER DAN JUSTICE COLLABORATORS PADA PENGUNGKAPAN KASUS KORUPSI BERBASIS NILAI KEADILAN," Jurnal Pembaharuan Hukum, vol. IV, 2017, http://www.mahfud. hlm 132.
} 
Dinyatakan dalam Surat Edaran Mahkamah Agung Nomor 4 Tahun 2011 tentang Perlakuan bagi Pelapor Tindak Pidana (Whistleblower) dan Saksi Pelaku yang Bekerja Sama (Justice Collaborator) di dalam Perkara Tindak Pidana Tertentu (SEMA No 4 Tahun 2011), pada angka 8 (a dan b) ditegaskan beberapa pedoman untuk menentukan kriteria Whistleblower yakni sebagai berikut:

1. Yang bersangkutan merupakan pihak yang mengetahui dan melaporkan tindak pidana tertentu sebagaimana dimaksud dalam SEMA ini dan bukan merupakan bagian dari pelaku kejahatan yang dilaporkannya;

2. Apabila pelapor tindak pidana dilaporkan pula oleh terlapor maka penanganan perkara atas laporan yang disampaikan oleh pelapor tindak pidana didahulukan dibanding laporan dari terlapor. Bahwa yang menjadi permasalahan selama ini dalam mengungkap kasus-kasus besar di Indonesia dibutuhkan saksi yang mengetahui keterlibatan seseorang khususnya dalam kasus korupsi, akan tetapi untuk menjadi seorang saksi yang mau bekerja sama dengan pihak penegak hukum tentunya tidak mudah karena semua itu beresiko tinggi.

\section{Perlindungan Hukum Terhadap Justice Collaborator dan Whistleblower dalam Tindak Pidana Korupsi}

Jenis perlindungan yang mungkin dapat diperoleh seorang whistleblower dan justice collaborator adalah perlindungan terhadap tuntutan pidana dan/atau perdata dari laporannya, kemudian juga dapat berupa perlindungan terhadap tuntutan pidana dan/atau perdata atas kasus atau perkara yang telah dilaporkannya, dan juga perlindungan dari tuntutan pidana dan/atau perdata atas kasus yang lain. Ada pun beberapa model perlindungan yang berorientasi kepada pasal 37 ayat (3) Konvensi PBB Anti Korupsi tahun 2003 yang diratifikasi di Indonesia dengan Undang-Undang Nomor 7 tahun 2006, yaitu:

1) Model hak-hak prosedural atau model partisipasi langsung atau aktif (the procedural rights model/ partie civile model /civil action system).

2) Model pelayanan atau model partisipasi secara tidak langsung atau model pasif (the services model).

3) Model Persuasif/Partisipatif

4) Model Penjatuhan Pidana Bersyarat

Mahkamah agung telah menunjukkan bentuk komitmennya dalam mendukung perlindungan saksi dan korban dengan menerbitkan SEMA Nomor 4 Tahun 2011 tentang perlakuan bagi pelapor tindak pidana (whistleblower) dan saksi pelaku yang bekerjasama (justice collaborator) dalam tindak pidana tertentu yang menjadi landasan hukum dan acuan bagi pengadilan untuk memberikan perlindungan kepada justice collaborator dan whistleblower. SEMA No.4/2011 tentang perlakuan bagi pelapor tindak pidana (whistleblower) dan saksi pelaku yang bekerjasama (justice collaborator) dalam perkara tindak pidana tertentu.

Bentuk perlindungan dan reward yang diberikan oleh SEMA kepada whistleblower berupa jika yang dilaporkan melaporkan balik whistleblower, maka penanganan kasus yang dilaporkan whistleblower harus didahulukan daripada kasus yang dilaporkan oleh terlapor. ${ }^{22}$ Sementara itu, bentuk perlindungan dan reward yang diberikan kepada justice collaborator

\footnotetext{
22 Nixson Syafruddin, Kalo Tan Kamello, and Mahmud Mulyadi, "PERLINDUNGAN HUKUM TERHADAP WHISTLEBLOWER DAN JUSTICE COLLABORATOR DALAM UPAYA PEMBERANTASAN TINDAK PIDANA KORUPSI,” USU Law Journal, vol. II, 2013.
} 
dalam SEMA ini ditentukan apabila: ${ }^{23}$

a. Seorang yang bersangkutan merupakan salah satu pelaku tindak pidana tersebut mengakui kejahatan yang dilakukannya, bukan pelaku utama, serta memberikan keterangan sebagai saksi dalam proses peradilan.

b. Jaksa penuntut umum dalam tuntutannya menyatakan bahwa yang bersangkutan telah memberikan keterangan dan bukti-bukti yang sangat signifikan sehingga penyidik dan/ atau penuntut umum dapat mengungkap tindak pidana yang dimaksud secara efektif, mengungkap pelaku-pelaku lainnya yang memiliki peran lebih besar dan/ atau mengembalikan asset-aset atau hasil suatu tindak pidana.

c. Atas bantuannya tersebut, hakim dalam memutus perkara terhadap justice collaborator tersebut dapat mempertimbangkan untuk menjatuhkan pidana percobaan bersyarat khusus dan/ atau menjatuhkan pidana berupa pidana percobaan bersyarat khusus dan/ atau menjatuhkan pidana berupa penjara paling ringan dari terdakwa lainnya yang terbukti bersalah dalam perkara yang dimaksud.

Peraturan bersama Tahun 2011 meyebut justice collaborator dengan istilah saksi pelaku yang bekerjasama. Peraturan bersama ini telah memberikan pengertian mengenai justice collaborator yang terdapat pada Pasal 1 Ayat 3, yaitu:

"Saksi pelaku yang bekerjasama adalah saksi yang juga sebagai pelaku suatu v tindak pidana atau akan terjadinya suatu tindak pidana untuk mengembalikan aset-aset atau hasil suatu tindak pidana kepada Negara dengan memberikan informasi kepada aparat penegak hukum serta memberikan kesaksian di dalam proses peradilan." 24

Bambang Irawan menyatakan, peraturan bersama ini menjamin Justice Collaborator akan memperoleh perlindungan fisik, psikis, dan hukum sebagaimana diatur dalam undangundang yang berlaku penanganan secara khusus dalam hal pemisahan tempat penahanan, pembebasan perkara yang terpisah, penundaan penuntutan, penundaan proses hukum dan memberikan kesaksian di depan persidangan tanpa menunjukkan wajah/identitasnya, serta pemberian penghargaan dalam hal keringanan penuntutan hukum termasuk hukum percobaan, pemberian remisi tambahan dan hak narapidana lain. ${ }^{25}$

Terkait dengan posisi atau kedudukan dari saksi pelaku yang bekerjasama (justice collaborator) yang seringkali terancam, maka dari itu untuk mencegah terjadinya ancaman itu maka aparat penegak hukum untuk pertama kali mengambil tindakan perlindungan hukum berupa merahasiakan identitas dari justice collaborator tersebut serta tidak memisahkan terlebih dahulu berkas perkara. Antara berkas perkara si justice collaborator dengan berkas perkara tersangka maupun terdakwa yang akan diungkapnya, langkah pencegahan awal ini bertujuan agar tidak timbul kecurigaan maupun terjadi ancaman dari tersangka maupun terdakwa yang akan diungkapkan kasusnya tersebut, serta memberikan hak-hak saksi yang terdapat dalam Kitab Undang-Undang Hukum Acara Pidana maupun hak-hak saksi yang terdapat dalam Undang-Undang Nomor 31 Tahun 2014 tentang perubahan Undang-Undang Nomor 13 Tahun 2006 tentang Perlindungan Saksi dan Korban.

UU No. 13/2006 dalam ketentuan umumnya telah menyatakan bahwa Lembaga Perlindungan Saksi dan Korban, yang selanjutnya disingkat menjadi LPSK, adalah lembaga yang bertugas dan berwenang untuk memberikan perlindungan dan hak-hak lain kepada saksi dan atau korban sebagaimana diatur dalam Undang-Undang. Maka dengan ini peranan LPSK

\footnotetext{
${ }^{23}$ Surat Edaran Mahkamah Agung (SEMA) Nomor 4 Tahun 2011 tentang Perlakuan bagi Whistleblower dan Justice Collaborator di dalam perkara tindak pidana tertentu.

${ }^{24}$ Peraturan Bersama Menteri Hukum dan Hak Asasi Manusia Republik Indonesia, Jaksa Agung Republik Indonesia, Kepala Kepolisian Republik Indonesia, Komisi Pemberantasan Korupsi Republik Indonesia, Ketua Lembaga Perlindungan Saksi dan Korban Republik Indonesia Tahun 2011 tentang Perlindungan Bagi Pelapor, Saksi Pelapor dan Saksi Pelaku yang Bekerjasama.

${ }^{25}$ Bambang Irawan, Jaksa Pratama Bidang Pidana Khusus Kejaksaan Tinggi Lampung. Lampung, 12 Oktober 2018, pukul $09.30 \mathrm{WIB}$
} 
ialah untuk memberi perlindungan hukum terhadap seorang justice collaborator berdasarkan peraturan perundang-undang yang berlaku. Dalam penjelasan umum UU No. 31/2014 jo. UU No. 13/2006, menyatakan bahwa dalam rangka menumbuhkan partisipasi masyarakat untuk mengungkap tindak pidana, perlu diciptakan iklim yang kondusif dengan cara memberikan perlindungan hukum dan keamanan kepada setiap orang yang mengetahui atau menemukan suatu hal yang dapat membantu mengungkap tindak pidana yang telah terjadi, serta melaporkan hal tersebut kepada penegak hukum. Pelapor tersebut harus diberi perlindungan hukum dan keamanan yang memadai atas laporannya, sehingga tidak merasa terancam atau tertekan baik hak-hak nya maupun keselamatan dirinya.

\section{Kempulan dan Saran}

\section{Kesimpulan}

a) Persamaan antara Justice collaborator dan whistleblower dalam tindak pidana korupsi dapat dilihat, antara lain: Pertama yaitu visi dan misi adalah mengungkap tindak pidana korupsi yang terjadi dan kedua jaminan perlindungan fisik, psikis dan hukum.

b) Perbedaan antara Justice collaborator dan whistleblower dalam tindak pidana korupsi dapat dilihat, antara lain: Pertama, yaitu Subjek Justice collaborator adalah salah satu pelaku tindak pidana, bukan pelaku utama dan subjek whistleblower adalah mantan atau masih sebagai pagawai suatu instansi. Kedua, motivasi Justice collaborator adalah kooperatif dan motivasi whistleblower adalah kesadaran diri sendiri. Ketiga, dalam hukum acara Justice collaborato rmemberikan keterangan dalam persidangan dan whistleblower memberikan keterangan di luar persidangan. Keempat, jaminan perlindungan Justice collaborator diketahui oleh media dan dilindungi oleh UndangUndang dan whistleblower tertutup dengan media.

c) Perlindungan hukum antara Justice collaborator dan Whistleblower yaitu dengan aparat mengambil tindakan pertama kali berupa perlindungan hukum merahasiakan identitas dari saksi dengan cara tidak menyebutkan dari mana sumber-sumber data yang didapat apabila data tersebut didapat dari saksi yang melapor kemudian memberikan pengamanan terhadap saksi dalam proses persidangan dan memperoleh perlindungan fisik, psikis, dan hukum sebagaimana diatur dalam Undang-Undang. Sedangkan sampai saat ini perlindungan terhadap Whistleblower di Indonesia belum ada peraturan perundang-undangan yang mengatur secara khusus tentang Whistleblower. Lemahnya jaminan perlindungan hukum terhadap peranan penting seorang whistleblower dalam proses peradilan pidana guna mengungkap kebenaran materiil dari suatu tindak pidana, diperlukan adanya suatu aturan hukum yang secara rinci dan tegas mengatur tentang perlindungan bagi whistleblower.

\section{Saran}

a) Masyarakat wajib berperan aktif dan peduli untuk mendukung penuh pemberantasan tindak pidana korupsi dengan cara ikut ambil peran untuk memberitahukan perbuatan korupsi yang terjadi baik didalam tempat kerja atau dilingkungan masyarakat.

b) Masyarakat yang ambil bagian menjadi justice collaborator dan whistleblower harus mendapatkan jaminan perlindungan yang serius, bukan hanya didalam persidangan saja melainkan diluar persidangan berdasarkan Undang-Undang yang mengatur mengenai perlindungan saksi.

c) Bagi instansi yang berwenang yang terkait, diharapkan dapat meningkatkan upayaupaya perlindungan hukum secara khusus terhadap whistleblower, sehingga dapat terealisasikan hak-haknya sampai proses pemeriksaan perkara tindak pidana korupsi tersebut berakhir dan segera membentuk lembaga khusus yang menaungi disetiap 
daerah di Indonesia agar terakomodirnya perlindungan saksi dan korban tersebut.

d) Pemerintah harus memberikan hadiah (reward) kepada masyarakat yang telah berperan terhadap pemberantasan tindak pidana korupsi dalam hal memberi informasi kepada penegak hukum mengenai dugaan tindak pidana korupsi merujuk pada Peraturan Pemerintah Nomor 43 Tahun 2018 tentang tata cara pelaksanaan peran serta masyarakat dan pemberian penghargaan dalam pencegahan dan pemberantasan tindak pidana korupsi.

\section{Daftar Pustaka}

A. Buku

Halim, 2004, Pemberantasan Korupsi, Jakarta: Rajawali Press.

Hamzah, Andi. Korupsi di Indonesia, Jakarta: Sinar Grafika.

Prodjodikoro, Wirjono. Tindak-Tindak Pidana Tertentu di Indonesia, Jakarta- Bandung: Eresco.

Wijaya, Firman. 2012, Whistle Blower dan Justice Colaborator dalam Perspektif Hukum, Jakarta:

Penaku.

B. Jurnal

Airlangga, Shandi Patria. "HAKIKAT PENGUASA DALAM NEGARA HUKUM DEMOKRATIS THE NATURE OF THE AUTHORITIES IN A DEMOCRATIC RULE OF LAW." Cepalo, 2019. https://doi.org/10.25041/cepalo.v3no1.1783.

Ahmad Yunus, "Penetapan Pelaku Tindak Pidana Korupsi Sebagai Justice Collaborator." Simbur Cahaya," accessed October 16, 2020, http://journal.fh.unsri.ac.id/index.php/simburcahaya/article/view/54/54. hlm 4762.

Eko Soponyono, Pujiyono, "Kebijakan Formulasi Hukum Pidana Terhadap 'Justice Collaborator' Dalam Tindak Pidana Korupsi Di Indonesia." Diponegoro Law Journal, Vol. 1 No. 4, 2020: 1-11, https://ejournal3.undip.ac.id/index.php/dlr/article/view/288/291.

Fitriani, Nur. "TINJAUAN YURIDIS KEKUATAN PEMBUKTIAN KETERANGAN SAKSI ANAK DALAM PERSIDANGAN PERKARA PIDANA JURIDICAL REVIEW OF THE POWER OF EVIDANCE OF CHILDREN'S WITNESS EVENTS IN CRIMINAL TRIALS.” JURNAL LEGALITAS. Vol. 12, January 3, 2019. http://ejurnal.ung.ac.id/index.php/JL/article/view/5416.

Gunawan, Yopi, and Universitas Singaperbangsa Karawang. "PERAN DAN PERLINDUNGAN WHISTLEBLOWER (PARA PENGUNGKAP FAKTA) DALAM RANGKA MEMBERANTAS TINDAK PIDANA KORUPSI DI INDONESIA." Law Review. Vol. XVIII, May 18, 2019. https://ojs.uph.edu/index.php/LR/article/view/1201.

Indriana, Yayan. "Pengembalian Ganti Rugi Keuangan Negara Pada Perkara Tindak Pidana Korupsi." Cepalo 2, no. 2 (September 12, 2019). https://jurnal.fh.unila.ac.id/index.php/cepalo/article/view/1769.

Moejijat, "Kesesuaian Upaya Pembuktian Jaksa Penuntut Umum Terhadap Tindak Pidana Pembunuhan Berdasarkan Alat - Alat Buktiyang Sah Dengan Ketentuan Pasal 184 Kuhap (Studi Putusan Nomor: 171/PID.B/2012/PN.Mgt)." Verstek, accessed October 16, 2020, https://jurnal.uns.ac.id/verstek/article/view/39115/25801https://jurnal.uns.ac.id/verstek/arti cle/view/39115/25801.

Muhammad, Rusli. "Pengaturan Dan Urgensi Whistle Blower Dan Justice Collaborator Dalam Sistem Peradilan Pidana." Jurnal Hukum IUS QUIA IUSTUM. Vol. 22, 2015. https://journal.uii.ac.id/IUSTUM/article/view/5117.

Mulyadi, Lilik. "Perlindungan Hukum Whistle-Blower Dan Justice Collaborator Dalam Upaya Penanggulangan Organized Crime Di Indonesia Masa Mendatang." PADJADJARAN 
Jurnal Ilmu Hukum (Journal of Law) 1, no. 3 (2014): 578-97. https://doi.org/10.22304/pjih.v1n3.a9.

Airlangga, Shandi Patria. "HAKIKAT PENGUASA DALAM NEGARA HUKUM DEMOKRATIS THE NATURE OF THE AUTHORITIES IN A DEMOCRATIC RULE OF LAW." Cepalo, 2019. https://doi.org/10.25041/cepalo.v3no1.1783.

Ahmad Yunus, "Penetapan Pelaku Tindak Pidana Korupsi Sebagai Justice Collaborator." Simbur Cahaya," $\quad$ accessed 2020 , http://journal.fh.unsri.ac.id/index.php/simburcahaya/article/view/54/54. hlm 4762.

Eko Soponyono, Pujiyono, "Kebijakan Formulasi Hukum Pidana Terhadap 'Justice Collaborator' Dalam Tindak Pidana Korupsi Di Indonesia." Diponegoro Law Journal, Vol. 1 No. 4, 2020: 1-11, https://ejournal3.undip.ac.id/index.php/dlr/article/view/288/291.

Fitriani, Nur. "TINJAUAN YURIDIS KEKUATAN PEMBUKTIAN KETERANGAN SAKSI ANAK DALAM PERSIDANGAN PERKARA PIDANA JURIDICAL REVIEW OF THE POWER OF EVIDANCE OF CHILDREN'S WITNESS EVENTS IN CRIMINAL TRIALS." JURNAL LEGALITAS. Vol. 12, January 3, 2019. http://ejurnal.ung.ac.id/index.php/JL/article/view/5416.

Gunawan, Yopi, and Universitas Singaperbangsa Karawang. "PERAN DAN PERLINDUNGAN WHISTLEBLOWER (PARA PENGUNGKAP FAKTA) DALAM RANGKA MEMBERANTAS TINDAK PIDANA KORUPSI DI INDONESIA." Law Review. Vol. XVIII, May 18, 2019. https://ojs.uph.edu/index.php/LR/article/view/1201.

Indriana, Yayan. "Pengembalian Ganti Rugi Keuangan Negara Pada Perkara Tindak Pidana Korupsi." Cepalo 2, no. 2 (September 12, 2019). https://jurnal.fh.unila.ac.id/index.php/cepalo/article/view/1769.

Moejijat, "Kesesuaian Upaya Pembuktian Jaksa Penuntut Umum Terhadap Tindak Pidana Pembunuhan Berdasarkan Alat - Alat Buktiyang Sah Dengan Ketentuan Pasal 184 Kuhap (Studi Putusan Nomor: 171/PID.B/2012/PN.Mgt)." Verstek, accessed October 16, 2020, https://jurnal.uns.ac.id/verstek/article/view/39115/25801https://jurnal.uns.ac.id/verstek/arti cle/view/39115/25801.

Muhammad, Rusli. "Pengaturan Dan Urgensi Whistle Blower Dan Justice Collaborator Dalam Sistem Peradilan Pidana." Jurnal Hukum IUS QUIA IUSTUM. Vol. 22, 2015. https://journal.uii.ac.id/IUSTUM/article/view/5117.

Mulyadi, Lilik. "Perlindungan Hukum Whistle-Blower Dan Justice Collaborator Dalam Upaya Penanggulangan Organized Crime Di Indonesia Masa Mendatang." PADJADJARAN Jurnal Ilmu Hukum (Journal of Law) 1, no. 3 (2014): 578-97. https://doi.org/10.22304/pjih.v1n3.a9.

Oktava, M Saoki. "EKSISTENSI KETETAPAN MPR/S DALAM HIERARKI PERATURAN PERUNDANG-UNDANGAN DI INDONESIA THE EXISTENCE OF MPR/S PROVISION IN HIERARCHY OF LAWS AND REGULATIONS IN INDONESIA." Jurnal IUS Kajian Hukum Dan Keadilan. Vol. 5, April 27, 2004. http://jurnalius.ac.id/ojs/index.php/jurnalIUS/article/view/434.

Pertiwi, Esti Kanti, and Noor Rahmad. "TINJAUAN NORMA HUKUM JUSTICE COLLABORATOR DAN WHISTLEBLOWER PADA TINDAK PIDANA KORUPSI." Perspektif. Vol. 25, May 29, 2020. https://www.

Rumambi, Deyv Ch. "KORUPSI DALAM PERSPEKTIF HUKUM ADMINISTRASI NEGARA." LEX ET SOCIETATIS. Vol. 2, August 15, 2014. https://ejournal.unsrat.ac.id/index.php/lexetsocietatis/article/view/5396.

Sukino, "PERTANGGUNGJAWABAN PENGGUNA ANGGARAN TERHADAP TINDAK PIDANA KORUPSI DANA BANTUAN SOSIAL (STUDI PUTUSAN MA.NO. 995 K/PID.SUS/2017)," Ensiklopedia of Journal 1, no. 4, July 8, 2019: 91-96, http://jurnal.ensiklopediaku.org.

Suratno, "PERLINDUNGAN HUKUM SAKSI DAN KORBAN SEBAGAI WHISTLEBLOWER DAN JUSTICE COLLABORATORS PADA PENGUNGKAPAN KASUS KORUPSI BERBASIS NILAI KEADILAN," Jurnal Pembaharuan Hukum, vol. IV, 2017, http://www.mahfud. 
Serikat, Di Amerika. "Urgensi Plea Bargaining System Dalam Pembaruan Sistem Peradilan Pidana Di Indonesia: Studi Perbandingan Plea Bargaining System." Jurnal Hukum IUS QUIA IUSTUM 27, no. 2020 (August 25, 2020): 388-409. https://doi.org/10.20885/iustum.vol27.iss2.art9.

Syafruddin, Nixson, Kalo Tan Kamello, and Mahmud Mulyadi. "PERLINDUNGAN HUKUM TERHADAP WHISTLEBLOWER DAN JUSTICE COLLABORATOR DALAM UPAYA PEMBERANTASAN TINDAK PIDANA KORUPSI.” USU Law Journal. Vol. II, 2013.

Ni Luh Made Dwi Pusparini, et al. "Urgensi Saksi Pelaku Yang Bekerjasama (Justice Collaborator) Dalam Tindak Pidana Korupsi,"Jurnal Interpretasi Hukum, Vol. 1., No. 1, 2020:

https://www.ejournal.warmadewa.ac.id/index.php/juinhum/article/view/2207/1606.

Oktava, M Saoki. "EKSISTENSI KETETAPAN MPR/S DALAM HIERARKI PERATURAN PERUNDANG-UNDANGAN DI INDONESIA THE EXISTENCE OF MPR/S PROVISION IN HIERARCHY OF LAWS AND REGULATIONS IN INDONESIA." Jurnal IUS Kajian Hukum Dan Keadilan. Vol. 5, April 27, 2004. http://jurnalius.ac.id/ojs/index.php/jurnalIUS/article/view/434.

Pertiwi, Esti Kanti, and Noor Rahmad. "TINJAUAN NORMA HUKUM JUSTICE COLLABORATOR DAN WHISTLEBLOWER PADA TINDAK PIDANA KORUPSI.” Perspektif. Vol. 25, May 29, 2020. https://www.

Rumambi, Deyv Ch. "KORUPSI DALAM PERSPEKTIF HUKUM ADMINISTRASI NEGARA." LEX ET SOCIETATIS. Vol. 2, August 15, 2014. https://ejournal.unsrat.ac.id/index.php/lexetsocietatis/article/view/5396.

Sukino, "PERTANGGUNGJAWABAN PENGGUNA ANGGARAN TERHADAP TINDAK PIDANA KORUPSI DANA BANTUAN SOSIAL (STUDI PUTUSAN MA.NO. 995 K/PID.SUS/2017)," Ensiklopedia of Journal 1, no. 4, July 8, 2019: 91-96, http://jurnal.ensiklopediaku.org.

Suratno, "PERLINDUNGAN HUKUM SAKSI DAN KORBAN SEBAGAI WHISTLEBLOWER DAN JUSTICE COLLABORATORS PADA PENGUNGKAPAN KASUS KORUPSI BERBASIS NILAI KEADILAN," Jurnal Pembaharuan Hukum, vol. IV, 2017, http://www.mahfud.

Serikat, Di Amerika. "Urgensi Plea Bargaining System Dalam Pembaruan Sistem Peradilan Pidana Di Indonesia: Studi Perbandingan Plea Bargaining System.” Jurnal Hukum IUS QUIA IUSTUM 27, no. 2020 (August 25, 2020): 388-409. https://doi.org/10.20885/iustum.vol27.iss2.art9.

Syafruddin, Nixson, Kalo Tan Kamello, and Mahmud Mulyadi. "PERLINDUNGAN HUKUM TERHADAP WHISTLEBLOWER DAN JUSTICE COLLABORATOR DALAM UPAYA PEMBERANTASAN TINDAK PIDANA KORUPSI.” USU Law Journal. Vol. II, 2013.

C. Peraturan Perundang-undangan/Dokumen Pemerintah

Ketetapan Majelis Permusyawaratan Republik Indonesia Nomor XI/MPR/1998 tentang Penyelenggara Negara yang Bersih dan Bebas Korupsi, Kolusi dan Nepotisme.

Kitab Undang-Undang Hukum Acara Pidana

Kitab Undang-Undang Hukum Pidana/

Peraturan Bersama Menteri Hukum dan Hak Asasi Manusia Republik Indonesia, Jaksa Agung Republik Indonesia, Kepala Kepolisian Republik Indonesia, Komisi Pemberantasan Korupsi Republik Indonesia, Ketua Lembaga Perlindungan Saksi dan Korban Republik Indonesia Tahun 2011 tentang Perlindungan Bagi Pelapor, Saksi Pelapor dan Saksi Pelaku yang Bekerjasama.

Surat Edaran Mahkamah Agung (SEMA) Nomor 4 Tahun 2011 tentang Perlakuan bagi Whistleblower dan Justice Collaborator di dalam perkara tindak pidana tertentu.

Undang-Undang Nomor 28 Tahun 1999 tentang Penyelenggara Penyelenggara Negara yang Bersih dan Bebas Korupsi, Kolusi dan Nepotisme.

Undang-Undang Nomor 31 Tahun 1999 sebagaimana diubah menjadi Undang-Undang Nomor 20 Tahun 2001 tentang Pemberantasan Tindak Pidana Korupsi/ 
Undang-Undang Nomor 31 Tahun 2014 tentang perubahan Undang-Undang Nomor 13 Tahun 2006 tentang Perlindungan Saksi dan Korban/

Undang-Undang Nomor 7 tahun 2006 tentang Ratifikasi Konvensi PBB Anti Korupsi Tahun 2003.

D. Internet

Bambang Irawan, Jaksa Pratama Bidang Pidana Khusus Kejaksaan Tinggi Lampung. Lampung, 12 Oktober 2018, pukul 09.30 WIB.

http://repository.widyatama.ac.id/bitstream/handle/10364/1024/bab12.pdf?sequence=3, diunduh pada hari Selasa, 16 Oktober 2018 Pukul 14.00 WIB 